\title{
Characterization of a gene encoding dihydrolipoamide dehydrogenase of the cyanobacterium Synechocystis sp. strain PCC 6803
}

\author{
Anke Engels† and Elfriede K. Pistorius \\ Author for correspondence: Elfriede K. Pistorius. Tel: +49521 5601. Fax: +495216410. \\ e-mail: E.Pistorius@Biologie.Uni-Bielefeld.DE
}

Universităt Bielefeld, Biologie VIII:

Zellphysiologie, 33501

Bielefeld, Germany

Keywords: dihydrolipoamide dehydrogenase, $l p d A$ gene, Synechocystis, cyanobacteria

\section{INTRODUCTION}

Dihydrolipoamide dehydrogenase (dihydrolipoamide: $\mathrm{NAD}^{+}$oxidoreductase, EC 1.8.1.4; LPD) belongs to the enzyme family called pyridine nucleotide disulfide oxidoreductases (Williams, 1991), which consist of lipoamide dehydrogenase (Williams, 1976; Carothers et

†Present address: Universităt Tübingen, Mikrobiologie/Biotechnologie, 72076 Tübingen, Germany.

Abbreviations: LPD, dihydrolipoamide dehydrogenase; PDC, pyruvate dehydrogenase complex.

The GenBank accession number for the sequence determined in this work is $\mathbf{Z 4 8 5 6 4 .}$ al., 1989), glutathione reductase (Schulz et al., 1978; Schirmer \& Schulz, 1987), mercuric reductase (Fox \& Walsh, 1982), thioredoxin reductase (Williams, 1976) and trypanothione reductase (Shames et al., 1986). These enzymes catalyse the electron transfer between pyridine nucleotides and disulfide compounds. All of them contain flavin and two redoxactive cysteines.

LPD is functionally involved in three multienzyme 2-oxo acid dehydrogenase complexes (pyruvate dehydrogenase, 2-oxoglutarate dehydrogenase and branched-chain 2-oxo acid dehydrogenase complexes) which catalyse the oxidative decarboxylation of 2-oxo acids (Williams, 1976). LPD is also a component of the glycine cleavage multienzyme complex (Kikuchi \& Hiraga, 1982; Bour- 
guignon et al., 1992). Besides the well-studied LPDs in the three 2-oxo acid dehydrogenase complexes and the glycine cleavage system, LPDs are present in some archaeobacteria (Danson et al., 1986; Danson, 1988) and parasites (Danson et al., 1987; Danson, 1988; Jackman et al., 1990; Else et al., 1993) in which the above-mentioned multienzyme complexes are absent. The function of these LPDs has remained uncertain. On the basis of results with Escherichia coli, which contains a cytoplasmic-membrane-associated LPD besides the LPD in the three 2-oxo acid dehydrogenase complexes (Richarme \& Heine, 1986), it was suggested that cytoplasmic-membrane-associated LPDs might have a fundamental role in membrane processes, such as transport of solutes into and out of the cell (Danson, 1988).

Previously, we reported on an LPD in the cyanobacterium Synechocystis sp. strain PCC 6803 (Engels et al., 1997). In many respects this LPD belongs to the class of typical LPDs. It contains noncovalently bound FAD, it is a homodimer of $105 \mathrm{kDa}$ and the $\mathrm{N}$-terminus shows significant homologies to the N-termini of other LPDs so far sequenced and also other pyridine nucleotide disulfide oxidoreductases. Immunocytochemical investigations gave evidence that the enzyme is present in the periplasmic space, between the cytoplasmic membrane and the peptidoglycan layer. The only other report on an LPD in a cyanobacterium is that by Serrano (1992), who isolated and characterized an LPD from the filamentous Anabaena sp. strain PCC 7119. The function of LPDs in cyanobacteria has so far remained uncertain. Serrano (1992) suggested that the LPD in Anabaena might be involved in a glycine cleavage system. On the other hand, Bothe \& Nolteernsting (1975) detected a low NAD-dependent pyruvate dehydrogenase activity in Anacystis nidulans (Synechococcus PCC 6301), suggesting the presence of a pyruvate dehydrogenase complex (PDC) in this unicellular cyanobacterium and thus implying the involvement of an LPD in such a complex. The detection of a cyanobacterial LPD located in the periplasmic space adds a new aspect to research on LPDs in cyanobacteria. To obtain further information about the possible function of the LPD in Synechocystis PCC 6803, the gene encoding this LPD was identified, sequenced and analysed. Moreover, an attempt was made to construct an LPD-free Synechocystis PCC 6803 mutant.

\section{METHODS}

Bacterial strains and growth conditions. Synechocystis sp. strain PCC 6803 was obtained from the Collection Nationale de Cultures de Micro-organismes, Institut Pasteur, Paris, France. The glucose-tolerant derivative of Synechocystis PCC 6803 (Synechocystis PCC 6803 Glu $^{\mathrm{T}}$; Williams, 1988) was a kind gift of Professor M. Rögner, Ruhr-Universität Bochum, Germany. Both wild-type strains and the heteroallelic mutant constructed in this paper were grown as previously described in BG11 medium with slight modifications (Engels et al., 1997). Growth of Synechocystis on agar plates was in BG11 medium (with slight modifications as above) containing $1 \%$ (w/v) agar (Gibco-BRL). When indicated, $10 \mu \mathrm{g}$ ampicillin $\mathrm{ml}^{-1}$ and/or $20 \mu \mathrm{g}$ kanamycin $\mathrm{ml}^{-1}$ were added to the growth medium.

Escherichia coli DH5 $\alpha$ MCR (Grant et al., 1990) was cultivated at $37^{\circ} \mathrm{C}$ in LB medium (Miller, 1972) or on PA plates containing, in $1 \mathrm{l}$ distilled water, $17.5 \mathrm{~g}$ antibiotic medium no. 3 (assay broth, Oxoid) and $16.0 \mathrm{~g}$ bacteriological agar (Oxoid). Where indicated, antibiotics were added at the following concentrations : $150 \mu \mathrm{g}$ ampicillin $\mathrm{ml}^{-1}$ and $50 \mu \mathrm{g}$ kanamycin $\mathrm{ml}^{-1}$.

Cell breakage and isolation of the membrane fraction. In general, all Synechocystis PCC 6803 cell types were grown for $2 \mathrm{~d}$, harvested by centrifugation and washed once in distilled water. Cells were then resuspended in HMCGS [50 mM HEPES/NaOH, pH 6.5, containing $30 \mathrm{mM} \mathrm{CaCl}_{2}, 10 \mathrm{mM}$ $\mathrm{MgCl}_{2}, 1 \mathrm{M}$ sucrose, $25 \%$ (w/v) glycerol, $25 \mu \mathrm{M}$ Pefabloc (Merck), $1 \mathrm{mM}$ benzamidine hydrochloride (Merck), $1 \mathrm{mM} \varepsilon_{-}$ aminocapronic acid (Merck) and benzonase $\left(0.4\right.$ units $\mathrm{ml}^{-1}$, Merck)] to give a final chlorophyll concentration of $0.3-0.4 \mathrm{mg}$ $\mathrm{ml}^{-1}$. Cell breakage was performed according to the method of Burnap et al. (1989) in a Bead Beater (Biospec Products). The membrane fraction, containing the thylakoid, cytoplasmic and outer cell membranes, was separated from the soluble protein fraction by centrifugation for $45 \mathrm{~min}$ at $95000 \mathrm{~g}$ and was then resuspended in HMCG (HMCGS from which sucrose was omitted) to a final chlorophyll concentration of $1 \mathrm{mg} \mathrm{ml}^{-1}$.

E. coli $\mathrm{DH} 5 \alpha \mathrm{MCR}$ was grown to a cell density corresponding to an $\mathrm{OD}_{580}$ of $0 \cdot 6-0 \cdot 8$, harvested by centrifugation, resuspended in $29 \mathrm{mM}$ Tris/ $\mathrm{HCl}, \mathrm{pH} 7.5$, and subsequently broken by treatment in a French press at $138 \mathrm{MPa}$. The soluble protein fraction from the periplasm fraction and the spheroplast fraction were isolated according to the procedure of Block \& Grossman (1988).

LPD activity measurements, protein determination, chlorophyll determination, SDSPAGE and immunoblotting. LPD activity was determined basically according to Serrano (1992). This assay is based on measurement of the rate of NADH oxidation at $25^{\circ} \mathrm{C}$ in the presence of a disulfide substrate for the LPD. The reaction was monitored by the decrease in $A_{340}$. The reaction mixture contained, in a final volume of $1 \mathrm{ml}$ : $100 \mu \mathrm{mol}$ Tris $/ \mathrm{HCl}, \mathrm{pH} 7 \cdot 0,3 \mu \mathrm{mol}$ DL-lipoamide (DL-6,8thioctic acid amide; added in $30 \mu \mathrm{l}$ dimethylsulfoxide/acetone, $1: 1, \mathrm{v} / \mathrm{v}), 0.5 \mu \mathrm{mol}$ EDTA, $10 \mu \mathrm{mol} 2$-mercaptoethanol, $0.2 \mu \mathrm{mol} \mathrm{NADH}$ and an adequate amount of enzyme. One unit of enzyme is defined as the amount which catalyses the oxidation of $1 \mu \mathrm{mol} \mathrm{NADH} \min ^{-1}$ at $25^{\circ} \mathrm{C}$ under the above conditions.

Protein was determined according to Smith et al. (1985) and chlorophyll according to Grimme \& Boardman (1972). SDSPAGE was performed according to Laemmli (1970). Protein samples for SDS-PAGE were denatured at $37^{\circ} \mathrm{C}$ for $30 \mathrm{~min}$. Immunoblotting was done as previously described, transferring proteins to nitrocellulose (Schleicher \& Schüll) and using the antibody raised against the isolated LPD from Synechocystis PCC 6803 (polyclonal antibody raised in a rabbit; Engels et al., 1997).

Oligonucleotide synthesis. The following oligonucleotide was designed on the basis of a partial N-terminal amino acid sequence (residues 2-7) of the LPD from Synechocystis PCC 6803 previously published (Engels et al., 1997), utilizing a codon usage dictionary of Synechocystis PCC 6803: 5'-CA A/G GA T/C TT T/C GA T/C TA T/C GA-3'. The oligonucleotide was synthesized with an Applied Biosystems 
(a)

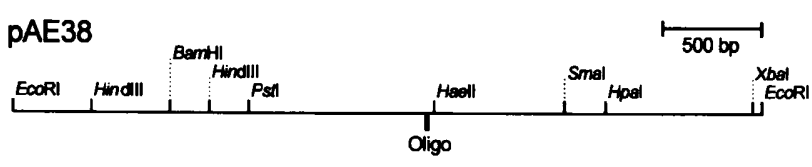

(b)

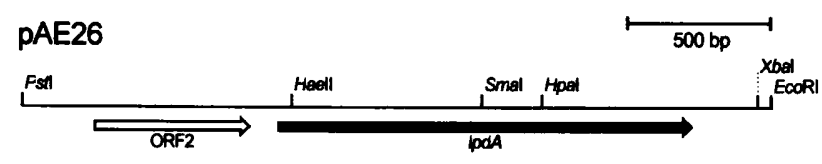

(c)

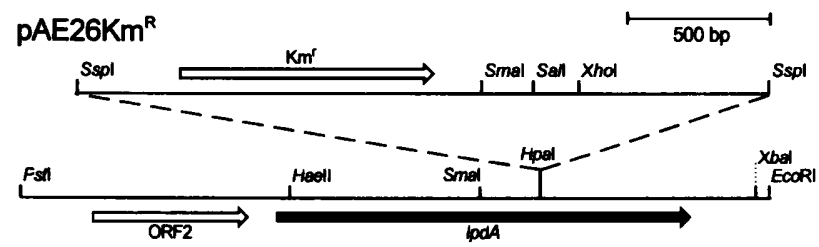

Fig. 1. Physical map of the IpdA gene region from Synechocystis PCC 6803 and insertional inactivation of the IpdA gene. (a) The pSVB30 derivative pAE38 contains a $3.8 \mathrm{~kb}$ ECORI fragment of Synechocystis PCC 6803 DNA carrying the IpdA gene. The position of the oligonucleotide probe is shown by the box. (b) pAE26 is a derivative of pAE38 lacking the Smal cleavage site in the multiple cloning site of pSVB30. It represents a 2600 bp Pstl-EcoRI fragment of pAE38 cloned into the Pstl/EcoRl-treated plasmid pSVB30. It contains the IpdA gene (ORF1) and ORF2. Size and orientation of the IpdA gene are shown by the arrow. (c) PAE26K $\mathrm{Km}^{R}$ is a derivative of PAE26. A $2.3 \mathrm{~kb}$ Sspl fragment from pJW31 containing a kanamycinresistance gene $\left(\mathrm{Km}^{\mathrm{R}}\right)$ originating from $\mathrm{Tn} 5$ was cloned into the single Hpal site (905 bp downstream from the putative start codon of the $(p d A)$. Size and orientation of the IpdA gene and the $\mathrm{Km}^{\mathrm{R}}$ gene are indicated by the arrow. This construct was then used to transform Synechocystis PCC $6803 \mathrm{Glu}^{\top}$.

DNA synthesizer model 380B using the phosphoramidite method (Beaucage \& Caruthers, 1981; Matteucci \& Caruthers, 1981) and purified as recommended by the manufacturer. The oligonucleotide was labelled with the DIG (digoxigenin) oligonucleotide $3^{\prime}$ end-labelling kit and detected with the DIG DNA labelling and detection kit (Boehringer Mannheim).

DNA isolation, cloning, sequencing and analysis. Total DNA of Synechocystis PCC 6803 was isolated by the Sarkosyl method and purified by the phenol extraction procedure (Williams, 1988; Sambrook et al., 1989). DNA was digested with EcoRI and size-fractionated on agarose gels. Recovery of the fragments was achieved by using the Jetsorb gel extraction kit from Genomed. The size-fractionated fragments of total DNA were cloned into EcoRI-linearized vector plasmid pSVB30 (Arnold \& Pühler, 1988). The details of plasmid construction (pSVB30 derivatives) are given in Fig. 1.

Cloning procedures, Southern blotting, and recombinant DNA methods were performed using established techniques (Sambrook et al., 1989). Subclones of the resulting hybrid plasmid were made by using the Pharmacia double-stranded nested deletion kit. These subclones were used for sequencing on an ALF Sequencer (Pharmacia). The enzymes used in this study were purchased from Boehringer, Bethesda Reseach
Laboratories or Pharmacia. All reactions were performed following the recommendations of the corresponding manufacturer.

Computer analysis. Nucleic acid sequences were analysed using the Staden Software package (Staden, 1986). The deduced protein sequence was analysed using the program PC/Gene (Release 6.80, 1993; IntelliGenetics). Related protein sequences were searched for in the SWISS-PROT, PIR and GenBank databases with the BLAST software (Altschul et al., 1990).

Construction of Synechocystis PCC 6803 mutant with an insertionally inactivated $I p d A$ gene. To inactivate the $l p d A$ gene, a $2.6 \mathrm{~kb}$ PstI-EcoRI fragment of plasmid pAE38 carrying the $I p d A$ gene cloned into vector plasmid pSVB 30 was chosen (Fig. 1a, b). For insertional inactivation of the $l p d A$ gene a $2 \cdot 3 \mathrm{~kb} S s p \mathrm{I}$ fragment from plasmid $\mathrm{pWJ} 31$ (a kind gift from $\mathrm{Dr}$ W. Jäger, Lehrstuhl für Genetik, Universität Bielefeld; unpublished results) was used. This DNA fragment carries a gene from $\operatorname{Tn} 5$ which codes for an aminoglycoside-3'phosphotransferase mediating resistance to kanamycin and neomycin (Jorgensen et al., 1979). This fragment was cloned into the single $\mathrm{HpaI}$ site of the lpdA gene (905 bp downstream of the start codon). Subsequently, the construct was transferred to $E$. coli $\mathrm{DH} 5 \alpha \mathrm{MCR}$, and clones with the interrupted $l p d A$ gene were identified by screening for double resistance (ampicillin resistance encoded by the vector; kanamycin resistance encoded by the Tn5 fragment) and subsequent restriction analysis. Detection was achieved with the synthetic oligonucleotide. This resulted in clones containing the kanamycin-resistance gene inserted either in the same or in the opposite direction as the $l p d A$ gene. Only the construct carrying the kanamycin-resistance gene in the same direction as the IpdA gene successfully transformed Synechocystis. This plasmid was called pAE26Km ${ }^{R}(7 \cdot 2 \mathrm{~kb})$ (Fig. 1c). The further protocol for construction of the Synechocystis mutant was basically the same as previously described for construction of an MSP-free Synechocystis PCC 6803 mutant (Engels et al., 1994).

\section{RESULTS AND DISCUSSION}

\section{Identification and characterization of the gene encoding the LPD from Synechocystis PCC 6803}

The gene encoding the LPD from Synechocystis sp. strain PCC 6803 was detected by an oligonucleotide designed on the basis of part of an N-terminal amino acid sequence of the enzyme (Engels et al., 1997) in Southern hybridization experiments. Analysis of Synechocystis total DNA digested with different restriction enzymes revealed the presence of a single copy of the putative gene (Fig. 2). A $3.8 \mathrm{~kb}$ EcoRI fragment was cloned in the vector pSVB30, yielding pAE38 (Fig. 1a).

A 2609 bp (PstI-EcoRI) fragment (Fig. 1b) containing an ORF (ORF2) and the lpdA gene (ORF1) was subcloned and sequenced (database accession number Z48564). ORF2 starts at base position 262 with an ATG start codon and terminates at base position 801 with a TAA stop codon. No significant homologies to other so far sequenced proteins were found, and the function of this ORF remains to be elucidated.

ORF1, encoding LPD, consists of 1745 bp (GC content $52.42 \mathrm{~mol} \%$ ); it starts at base position 900 with an ATG start codon and terminates at base position 2324 with a 


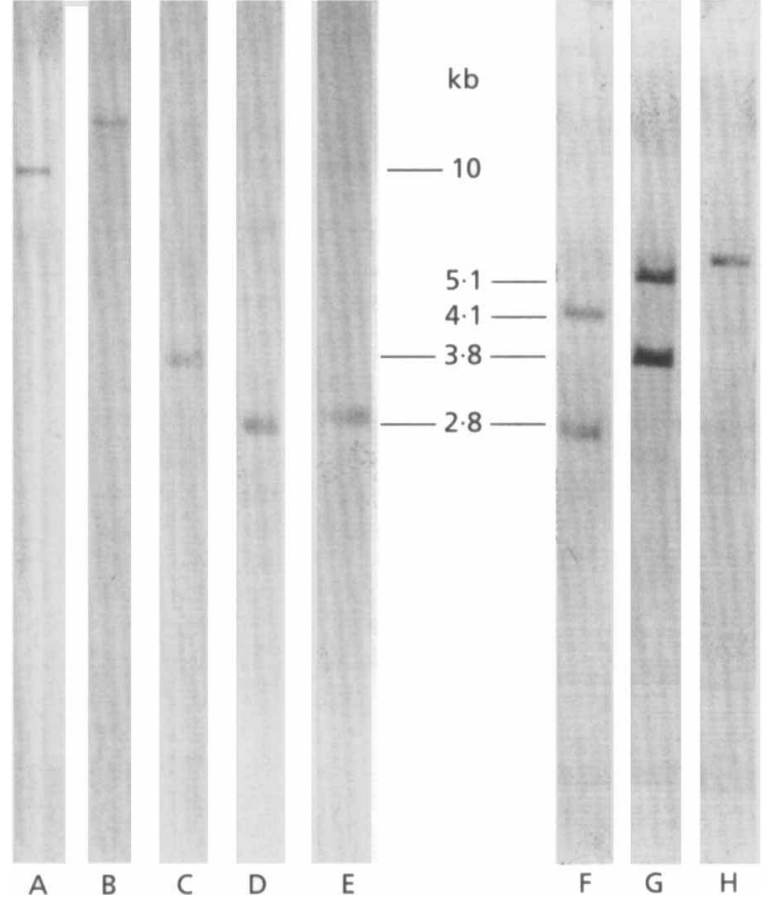

Fig. 2. Southern blot of total DNA from wild-type Synechocystis PCC 6803 and from the heteroallelic mutant Synechocystis PCC $6803 \mathrm{Glu}^{\top} \mathrm{KC}$ with various endonucleases. Genomic DNA from Synechocystis PCC 6803 was digested with HindllI (10 kb fragment, lane A), BamHI (16 kb fragment, lane B), EcoRI (3.8 kb fragment, lane C), EcoRl/Hindlll ( $2.8 \mathrm{~kb}$ fragment, lane D), and EcoRI/BamHI (3.0 kb fragment, lane E). Genomic DNA from Synechocystis PCC $6803 \mathrm{Glu}^{\top}$ KC was digested with EcoRl/HindIII ( 2.8 and $4.1 \mathrm{~kb}$ fragments corresponding to the native and the cassette-inactivated IpdA gene, respectively, lane F), EcoRI ( 3.8 and $5.1 \mathrm{~kb}$ fragments corresponding to the native and the cassette-inactivated IpdA gene, respectively, lane $G$ ), and Smal (fragment of $6.5 \mathrm{~kb}$ for both, lane $\mathrm{H}$ ). The IpdAcarrying fragment was detected with a DIG-labelled synthetic oligonucleotide synthesized according to an amino acid sequence of the $\mathrm{N}$-terminal region of the isolated LPD from Synechocystis PCC 6803.
TAA stop codon. Potential promoter sequences (a Pribnow box and -35 sequence) are found at base positions 10-14 and 27-32 upstream of the translational start. The presence of canonical promoter sequences for a $\sigma^{70}$-like transcription factor was corroborated by expression of the LPD protein in E. coli (see below). Amino acids $2-18$ of the deduced amino acid sequence of ORF1 are identical to the peptide sequence obtained by direct sequencing of the LPD protein (Engels et al., 1997), demonstrating that the authentic LPD-encoding gene from Synechocystis PCC 6803 had been identified. The gene was subsequently called $l p d A$.

The deduced LPD ORF codes for 474 amino acids, starting with methionine. Since protein sequencing gave a serine as the $\mathrm{N}$-terminal amino acid, it has to be concluded that the $\mathrm{N}$-terminal formylated methionine is post-translationally removed. The subsequent computer analysis of the $l p d A$ gene product was performed on the remaining 473 amino acids corresponding to a molecular mass of $50701 \mathrm{Da}$. When FAD is included in the calculation, the molecular mass is $51421 \mathrm{Da}$. This is in good agreement with the apparent subunit molecular mass of $55 \mathrm{kDa}$ obtained by SDS-PAGE. The calculated isoelectric point of the protein is $5 \cdot 17$. This agrees quite well with the tight binding of the acidic protein to anionbinding exchange columns during purification (Engels et al., 1997).

The hydrophobicity profile on the basis of Kyte \& Doolittle (1992) indicated that the LPD is a peripheral and not an integral membrane protein. This is in agreement with our biochemical investigations showing that the mild detergent sulfobetaine 12 , which does not release integral membrane proteins, will solubilize the LPD (Engels et al., 1997). In contrast, evaluation on the basis of Rao \& Argos (1986) or Eisenberg et al. (1984) suggested two potential transmembrane helices, at positions 9-25 and 323-341 or 8-28 and 178-198, respectively. Due to these different results from the

Table 1. Identities and similarities between selected pyridine nucleotide oxidoreductases and the LPD from Synechocystis PCC 6803

Similarity includes, besides identical amino acids, the residue groups $A / S / T, D / E, N / Q, R / K$, $\mathrm{I} / \mathrm{L} / \mathrm{M} / \mathrm{V}$ and $\mathrm{F} / \mathrm{Y} / \mathrm{W}$, respectively.

\begin{tabular}{|c|c|c|c|}
\hline Enzyme & $\begin{array}{l}\text { Identity } \\
\quad(\%)\end{array}$ & $\begin{array}{c}\text { Similarity } \\
(\%)\end{array}$ & Reference \\
\hline \multicolumn{4}{|l|}{ LPD } \\
\hline Human & $34 \cdot 8$ & $48 \cdot 3$ & Otulakowski \& Robinson (1987) \\
\hline Pea & $33 \cdot 4$ & $48 \cdot 1$ & Turner et al. (1992) \\
\hline Pseudomonas fluorescens & $32 \cdot 7$ & $43 \cdot 9$ & Benen et al. (1989) \\
\hline Clostridium magnum & $31 \cdot 9$ & $43 \cdot 2$ & Krüger et al. (1994) \\
\hline Alcaligenes eutrophus & $31 \cdot 4$ & $42 \cdot 6$ & Hein \& Steinbüchel (1994) \\
\hline \multicolumn{4}{|l|}{ Glutathione reductase } \\
\hline Arabidopsis thaliana & $26 \cdot 6$ & $35 \cdot 9$ & Kubo et al. (1993) \\
\hline \multicolumn{4}{|l|}{ Mercuric reductase } \\
\hline Staphylococcus aureus & $27 \cdot 4$ & $37 \cdot 1$ & Laddaga et al. (1987) \\
\hline
\end{tabular}




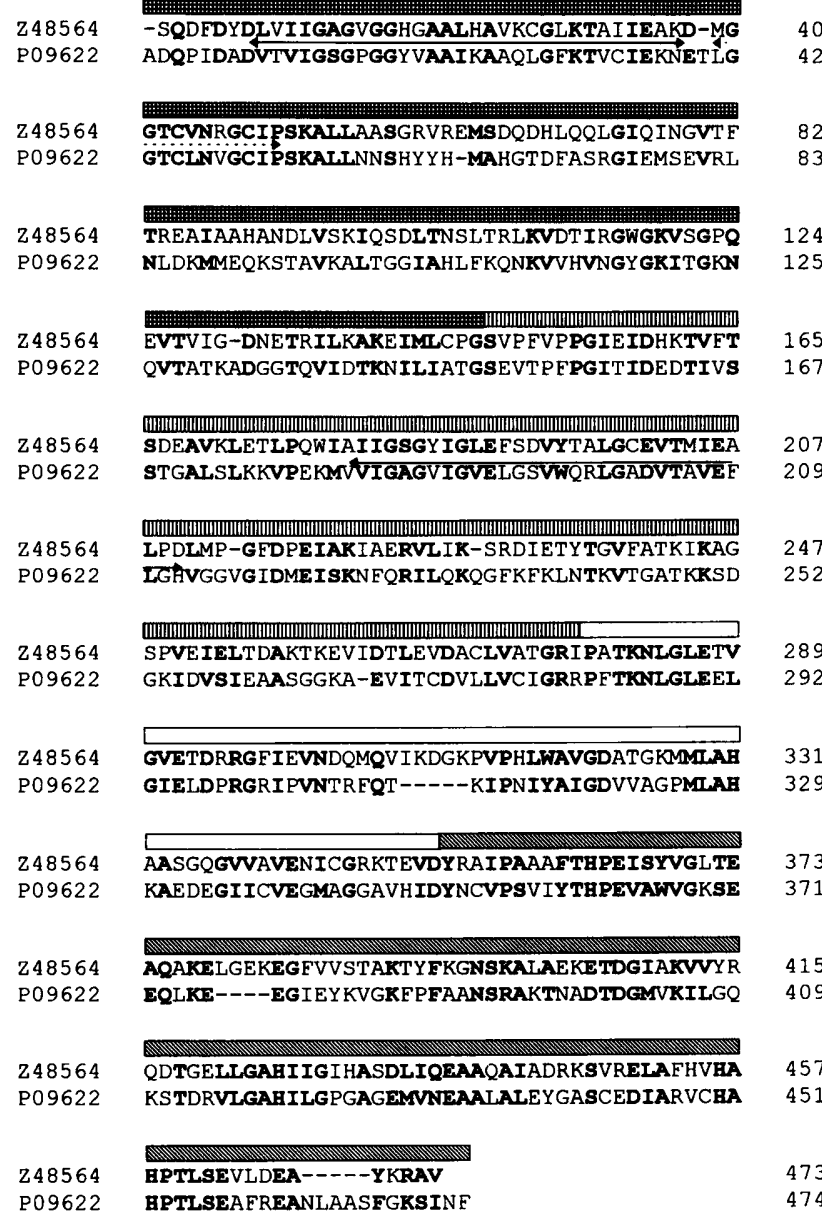

Fig. 3. Alignment of the LPD from Synechocystis PCC 6803 (GenBank accession number 248564 ) with the LPD from human erythrocytes (GenBank accession number P09622). Identical and similar (A/S/T; D/E; N/Q; R/K; I/L/MN ; F/YMN) amino acids are printed bold. A dashed line between amino acid residues (---.) indicates an introduced gap. Above the sequence the four domains of pyridine nucleotide disulfide oxidoreductases are indicated by boxes. Box with grid lines, FAD-binding domain; box with vertical lines, NAD-binding domain; open box, central domain; box with diagonal lines, interface domain. Arrows indicate the sequence of the adenosine-binding domain and a broken-line arrow indicates the active cysteine motif.

evaluation programs, no clear conclusion can be drawn. Hydrophobic regions in the FAD-binding domain have also been found in other pyridine nucleotide disulfide oxidoreductases (Thieme et al., 1981; Karplus \& Schulz, 1987).

\section{Homology analysis}

Comparison of the amino acid sequence of the LPD from Synechocystis PCC 6803 with protein sequences in the Protein Information Resource database revealed that the protein has similarities to enzymes belonging to the group of pyridine nucleotide disulfide oxidoreductases, especially to all LPDs so far sequenced. In Table 1 those LPDs with the highest homology to the
Synechocystis enzyme and in addition some oxidoreductases which are relevant for the discussion are listed. A computer alignment of the Synechocystis LPD with the LPD from human erythrocytes (Otulakowski \& Robinson, 1987) according to the algorithm of Myers \& Miller (1988) is shown in Fig. 3. The similarity between the primary structures of these two LPDs occurs in all four domains defined in pyridine nucleotide disulfide oxidoreductases (Carothers et al., 1989) on the basis of those oxidoreductases for which a threedimensional structure has been proposed, as for example for the LPDs from Pseudomonas fluorescens (Mattevi et al., 1993), Pseudomonas putida (Mattevi et al., 1992) and Azotobacter vinelandii (Mattevi et al., 1991), or for the glutathione reductase from human erythrocytes (Schulz et al., 1978). Those defined domains are the FAD-binding domain (residues 1-147 in the LPD from Synechocystis PCC 6803), the NAD-binding domain (residues 148-278), the central domain (residues 279354) and the interface domain (residues 353-473). The functional motif of the FAD-binding domain (GxGxxG/ AxxxG/A; residues 12-21) and of the redox-active cysteines (CxxxxC; residues 43-48: CVNRGC) are present in Synechocystis LPD.

Unusual for an LPD is the finding of a valine in position 44 after the first active cysteine in the Synechocystis enzyme. All other LPDs have a conserved lysine in this position (Mattevi et al., 1993). So far, only glutathione reductases have been shown to possess a valine in this position (Schulz et al., 1978). However, as in all other LPDs, a cysteine in position 77 is missing in the Synechocystis LPD. Such a cysteine is present in glutathione reductase, in which the two subunits are linked covalently by this cysteine, while the subunits in LPDs are not linked covalently. As expected, and as is the case for all other LPDs, within the NAD(P)-binding domain of oxidoreductases the basic amino acid residues which are involved in binding of the $2^{\prime}$ phosphoryl group of NADP (for example $\mathrm{A}^{207}, \mathrm{H}^{219}$ and $\mathrm{R}^{224}$ in the human glutathione reductase) are replaced by neutral amino acids in LPDs $\left(\mathrm{A}^{207}, \mathrm{~L}^{208}\right.$ and $\mathrm{P}^{213}$ in the Synechocystis enzyme). This region of sequence is likely to be important in discriminating between NAD (cofactor of LPD) and NADP (cofactor of glutathione reductase and mercuric reductase). In the $\mathrm{C}$-terminal region in position 458 the active histidine is found which according to Holmes \& Stevenson (1986) is essential for binding of the lipoyl group in the neighbouring transacetylase. This comparison shows that identity or conservative substitution of amino acids is especially notable for residues which are essential for binding the two cofactors (FAD and NAD), which are catalytically active or located close to the active centre, or which contribute to the interaction between the two subunits. The homologies are not restricted to these active-site regions but extend throughout the protein sequence, and only a few gaps had to be introduced to optimize the alignment.

A major difference of the Synechocystis LPD in comparison to other LPDs so far sequenced is that the Cterminal region downstream of the active histidine is 


\begin{tabular}{|c|c|c|c|}
\hline Synechocystis & 458 & HPTLSEVLDEAYKRAV & 473 \\
\hline Homo sapiens & 487 & HPTLSEAFREANLAASFGKSINF & 509 \\
\hline Sus scrofa & 487 & HPTLSEAFREANLAASFGKAINE & 509 \\
\hline Pisum sativum (a) & 480 & HPTMSEAIKEAAMA-TYDKPHSHLKSWLLLSSLVFI FVQGFTLTWRRYFVC & 529 \\
\hline Pisum sativum (b) & 480 & HPTMSEAIKEAAMA-TYDKP $\bar{H} I$ & 501 \\
\hline P. fluorescens & 450 & HPTLSEALHEAALAVNGHAI $\underline{\bar{H}}$ IANRKKR & 477 \\
\hline B. subtilis & 447 & HPTLGE ITMEAAEVAIGSPI프IVK & 470 \\
\hline P. carbinolicus & 449 & HPTLSEAVKEALDVDGAAVH & 470 \\
\hline B. stearotherm. & 446 & HPTLGE IAMEAAEVALGTPIHIITK & 470 \\
\hline P. putida (LPD-3) & 445 & HPTRSEALRQNAMNVDGMAMQ̄I & 466 \\
\hline S. aureus & 446 & HPTLGEMTMEAAEKAIGYPIHTM & 468 \\
\hline C. magnum & 554 & HPTVGEAMKENAI_AVNNQAIHMMNK & 578 \\
\hline A. vinelandii & 451 & HPALSEALHEAALAVSGHAI & 477 \\
\hline E. coli & 445 & HPTLHESVGLAAEVFEGS ITDILPNPKAKKK & 474 \\
\hline H. volcanii & 450 & HPT LAEAVMEAAENALGQAIHTLNR & 474 \\
\hline S. cerevisiae & 478 & HPTLSEAFKEANMAAYDKAI & 499 \\
\hline P. putida (LPD-Val) & 448 & HPTLSEALHEAALAVNGGAI & 475 \\
\hline P. putida (LPD-Glu) & 449 & HKAVHEG-HVAAENCAGNKAȲFDARVIPGVAYT & 480 \\
\hline T. brucei & 458 & HPTMSEAVKEACMACFAKT INF & 479 \\
\hline A. eutrophus & 567 & HPTLGESIGMAAEIYEGTCTDVPPPRKR & 594 \\
\hline
\end{tabular}

Fig. 4. C-termini of all LPDs sequenced so far. The C-terminus starting from the active histidine residue is given. The listing from top to bottom is according to the degree of similarity of other LPDs to the Synechocystis PCC 6803 LPD. Identical amino acids are written in bold letters. The histidine region which according to Mattevi et al. (1993) participates in an intermolecular hydrogen bridge to an N-terminal tyrosine of the other LPD subunit is underlined. For the C-terminal region of pea two diverging sequences are given according to Turner et al. (1992) (marked a in the figure) and to Bourguignon et al. (1992) (marked $b$ in the figure). The sequences are from the GenBank database: Synechocystis PCC 6803 (accession number Z48564; this paper), Homo sapiens (P09622), Sus scrofa (P09623), Pisum sativum (a) (S96804), Pisum sativum (b) (X63464), Pseudomonas fluorescens (A45796), Bacillus subtilis (P21880), Pelobacter carbinolicus (M01100), Bacillus stearothermophilus (X53560), Pseudomonas putida LPD-3 (P31046), Staphylococcus aureus (S19723), Clostridium magnum (L31844), Azotobacter vinelandii (P18925), Escherichia coli (P00391), Haloferax volcanii (Q04829), Saccharomyces cerevisiae (P09624), Pseudomonas putida LPD-Val (P31052), Pseudomonas putida LPD-Glu (A39406), Trypanosoma brucei (X70646), Alcaligenes eutrophus (U09865).

substantially shorter than in the other LPDs (Fig. 4). On the basis of mutant studies with the LPD from Pseudomonas fluorescens (Mattevi et al., 1993), this region is assumed to contribute to the dimer and redox stability of the enzyme. Moreover, two sequences with polar amino acids exist in the Synechocystis LPD (region 308-312: I, K, D, G, K and region 379-382: L, G, E, K) which are not found in any other of the LPDs so far sequenced. By comparing the primary structure of the Synechocystis LPD with the known three-dimensional structure of the LPD from P. fluorescens (Mattevi et al., 1993), a possible location between the $\beta$-sheets A5 and A6 and between the $\alpha$-helix 4.8 and $\beta$-sheet E3 can be suggested. Alterations in these regions should result in a modification of loop 5, which is assumed to be involved in the association of the P. fluorescens LPD with the transacetylase (Mattevi et al., 1993). These sequence deviations of the Synechocystis LPD from other LPDs so far sequenced might be an indication of an altered interaction with neighbouring proteins or of a completely different function of this extracellularly located cyanobacterial LPD.

\section{Attempt to generate an LPD-free Synechocystis PCC 6803 mutant}

As a first step in elucidating the possible function of the Synechocystis LPD we attempted to generate an LPDdeficient mutant by insertional inactivation of the $l p d A$ gene and subsequent homologous recombination into the wild-type genome of Synechocystis PCC 6803. With plasmid pAE26Km ${ }^{R}$, containing the $l p d A$ gene insertionally inactivated by a $2.3 \mathrm{~kb} S s p \mathrm{I}$ fragment from $\mathrm{pWJ} 31$, which carries a gene mediating resistance to kanamycin and neomycin (for details see Methods; Fig. 1c) we first tried to transform Synechocystis PCC 6803 (a strain which is not able to grow on glucose under photoheterotrophic conditions). However, we were not successful in obtaining transformants using either a natural transformation system, electroporation or transformation after $\mathrm{CaCl}_{2}$ treatment of the cells. Therefore, at this stage we switched to the glucose-tolerant strain Synechocystis PCC $6803 \mathrm{Glu}^{\mathrm{T}}$, which is able to grow on glucose under photoheterotrophic conditions (Williams, 1988). From all information so far available in the literature, these two Synechocystis strains are otherwise identical. The hybridization pattern of genomic DNA from these two strains after treatment with various restriction enzymes was identical (not shown).

Transformation of $\mathrm{CaCl}_{2}$-treated Synechocystis PCC $6803 \mathrm{Glu}^{\mathrm{T}}$ cells with pAE26 $\mathrm{Km}^{\mathrm{R}}$ resulted in $\mathrm{Km}^{\mathrm{R}} \mathrm{Ap}^{\mathrm{S}}$ transformants. Ninety-five percent of the single colonies had lost the vector-encoded ampicillin resistance, which implies that the desired double recombination event had occurred and that only the cyanobacterial DNA containing the internal drug resistance cassette had integrated into the genome. In an attempt to achieve segregation, repeated subculturing was performed. For this purpose five of the above colonies were transferred to liquid BG11 medium containing kanamycin and 
Table 2. Comparison of growth of Synechocystis PCC $6803 \mathrm{Glu}^{\top}$ and the heteroallelic mutant Synechocystis PCC $6803 \mathrm{Glu}^{\top} \mathrm{KC}$ under various conditions

Synechocystis cells were grown under normal growth conditions in BG11 medium with either nitrate or ammonium as nitrogen source. Additionally, the medium was supplemented with $5 \mathrm{mM}$ glucose or with $20 \mathrm{mM}$ HEPPS/ $\mathrm{NaOH}$ buffer, $\mathrm{pH} 7 \cdot 5$, where indicated. After $2 \mathrm{~d}$ the $\mathrm{pH}$ of the medium was determined. The last column in the table indicates whether cells grew $(+)$ or did not grow (-) under the chosen conditions.

\begin{tabular}{|llcc|}
\hline $\begin{array}{l}\text { Synechocystis } \\
\text { PCC 6803 }\end{array}$ & \multicolumn{1}{c}{$\begin{array}{c}\text { Supplements to nitrate-free } \\
\text { BGll }\end{array}$} & $\begin{array}{c}\text { pH of medium } \\
\text { after 2 d growth }\end{array}$ & Growth \\
\hline Wild-type $\left(\mathrm{Glu}^{\mathrm{T}}\right)$ & $\mathrm{KNO}_{3}$ & $7 \cdot 5$ & + \\
& $\mathrm{NH}_{4} \mathrm{Cl}$ & 7.5 & + \\
& $\mathrm{KNO}_{3}+$ glucose & $7 \cdot 5$ & + \\
& $\mathrm{KNO}_{3}+\mathrm{HEPPS} / \mathrm{NaOH}, \mathrm{pH} 7 \cdot 5$ & $7 \cdot 5$ & + \\
Heteroallelic & $\mathrm{KNO}_{3}$ & 6.3 & - \\
mutant $\left(\mathrm{Glu}{ }^{\mathrm{T}} \mathrm{KC}\right)$ & $\mathrm{NH}_{4} \mathrm{Cl}$ & 6.5 & - \\
& $\mathrm{KNO}_{3}+$ glucose & 6.2 & - \\
& $\mathrm{KNO}_{3}+\mathrm{HEPPS} / \mathrm{NaOH}, \mathrm{pH} 7.5$ & 7.5 & + \\
\hline
\end{tabular}

Table 3. Comparison of the LPD activity of Synechocystis PCC $6803 \mathrm{Glu}^{\top}$ and the heteroallelic mutant Synechocystis PCC $6803 \mathrm{Glu}^{\top}$ KC

Growth was for $2 \mathrm{~d}$ in BG11 medium containing $20 \mathrm{mM}$ HEPPS/ $\mathrm{NaOH}$ buffer, $\mathrm{pH} 7 \cdot 5$. After breaking the cells as described in Methods, LPD activity was determined in total cell extracts, in the membrane fraction and in the soluble protein fraction. One unit of enzyme was defined as $1 \mu \mathrm{mol} \mathrm{NADH}$ oxidized $\mathrm{min}^{-1}$ in the presence of $0.2 \mathrm{mM} \mathrm{NADH}$ and $3 \mathrm{mM}$ lipoamide at $25^{\circ} \mathrm{C}$.

\begin{tabular}{|lccc|}
\hline Preparation & \multicolumn{2}{c|}{$\begin{array}{c}\text { LPD activity in Synechocystis } \\
\text { [units (mg protein) }\end{array}$} \\
\cline { 2 - 4 } & PCC 6803 & $\begin{array}{c}\text { PCC 6803 } \\
\text { Glu }^{\mathrm{T}}\end{array}$ & $\begin{array}{c}\text { PCC 6803 } \\
\text { Glu }^{\mathrm{T}} \text { KC }\end{array}$ \\
\hline $\begin{array}{l}\text { Total cell extract } \\
\text { Membrane fraction }\end{array}$ & 0.024 & 0.022 & 0.012 \\
Soluble fraction & 0.019 & 0.018 & 0.010 \\
\hline
\end{tabular}

grown for several growth cycles. The cell suspension was diluted every $3 \mathrm{~d}$. After three such treatments the cells had died, implying that complete segregation was lethal. After trying a number of other growth conditions (various nitrogen sources and adding glucose to the medium), it became obvious that under all tested growth conditions mutant cells caused an acidification of the culture medium. The pH dropped from about $7 \cdot 5$ to $6 \cdot 5$, suggesting that the Synechocystis mutant cells cannot tolerate a slightly acidic medium (Table 2). Such an acidification of the medium was not observed with wildtype cells. To overcome this problem, the buffering capacity of the culture medium was increased by adding $20 \mathrm{mM}$ HEPPS/NaOH buffer, $\mathrm{pH} 7 \cdot 5$. Under such conditions the transformants could be cultivated over prolonged periods without damage (10-15 dilution cycles of $3 \mathrm{~d}$ ).

Partial characterization of these transformants showed that all of them were of the same phenotype. Thus, the results of only one transformant, called Synechocystis PCC $6803 \mathrm{Glu}^{\mathrm{T}} \mathrm{KC}$, will be presented. Southern blot analysis revealed the presence of both the wild-type lpdA gene $(2.8 \mathrm{~kb}$ fragment $)$ and the insertionally inactivated $l p d A$ gene $(4 \cdot 1 \mathrm{~kb}$ fragment : lane F of Fig. 2$)$. As shown in Table 3, the mutant had detectable levels of LPD activity, but the activity was only about half that of wild-type cells. The same conclusion could be drawn from the Western blot (Fig. 5). The LPD protein was detected in the mutant but the amount was reduced by at least $50 \%$. Thus, the transformant is heteroallelic. Selection occurred for viability (native $l p d A$ gene) and antibiotic resistance (cassette-inactivated $l p d A$ gene), implying that the $l p d A$ gene product is essential in Synechocystis PCC $6803 \mathrm{Glu}^{\mathrm{T}}$. This condition is possible because of the polyploid nature of Synechocystis PCC 6803, which contains six to eight chromosomal DNA copies (Williams, 1988). Other heteroallelic mutants have been obtained, for example after insertional inactivation of the gene encoding phosphoenolpyruvate carboxylase in Synechococcus PCC 7942 (Luinenburg \& Coleman, 1990; there referred to as a merodiploid mutant) and of the gene encoding the FUR protein in Synechococcus PCC 7942 (Ghassemian \& Straus, 1996).

\section{Expression of the Synechocystis LPD in E. coli}

To answer the question whether an active Synechocystis LPD was expressed, $E$. coli DH $5 \alpha \mathrm{MCR}$ transformants with plasmids pAE38 and pAE26, both containing the intact $l p d A$ gene, and also with plasmid pAE $26 \mathrm{Km}^{\mathrm{R}}$, containing the inactivated $l p d A$ gene, were analysed. As the results of Table 4 show, the $E$. coli cells transformed with pAE38 and pAE26 contained an about 20-30-fold 

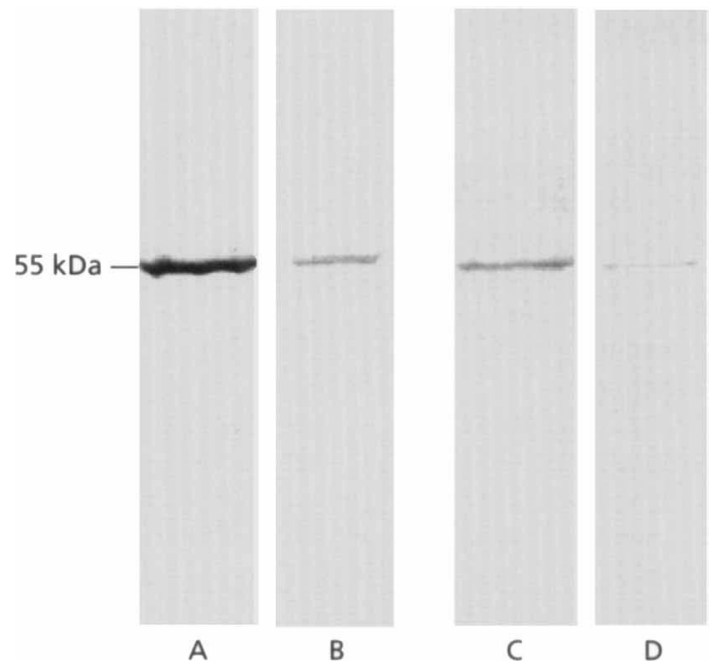

Fig. 5. Immunoblot for detection of the LPD protein in Synechocystis PCC $6803 \mathrm{Glu}^{\top}$ and in the heteroallelic mutant Synechocystis PCC $6803 \mathrm{Glu}^{\top}$ KC. Synechocystis total cell extracts were separated into a membrane fraction and a soluble protein fraction by centrifugation. After SDS-PAGE, proteins were transferred to nitrocellulose and immunostained with the antiLPD antiserum (dilution 1:1000). Lanes A and C, Synechocystis PCC $6803 \mathrm{Glu}^{\top}$ membrane fraction (lane A) and soluble protein fraction (lane $C$ ); lanes $B$ and $D$, heteroallelic mutant Synechocystis PCC $6803 \mathrm{Glu}^{\top} \mathrm{KC}$ membrane fraction (lane B) and soluble protein fraction (lane D). Each lane contained $30 \mu \mathrm{g}$ protein.

increased level of LPD activity. This clearly demonstrates that in E. coli an active, FAD-containing Synechocystis LPD was expressed. The LPD protein could also be detected by the anti-LPD antiserum (Fig. 6). As expected, E. coli cells transformed with pAE26Km ${ }^{R}$ did not have an elevated LPD level. Western blot analysis, however, revealed that an approximately $35 \mathrm{kDa} \mathrm{LPD}$ protein fragment was expressed which cross-reacted with the antiserum but which did not have LPD activity (Table 4, Fig. 6).

\section{Concluding remarks}

It was not possible to construct an $l p d A$ mutant of wildtype Synechocystis sp. PCC 6803. Also in a glucosetolerant mutant, Synechocystis sp. PCC $6803 \mathrm{Glu}^{\mathrm{T}}$, not

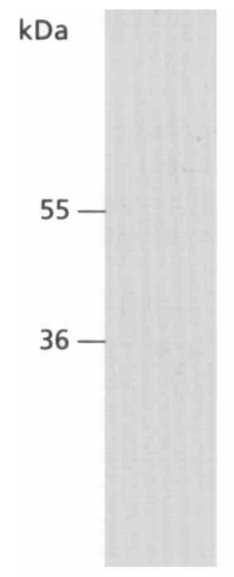

A

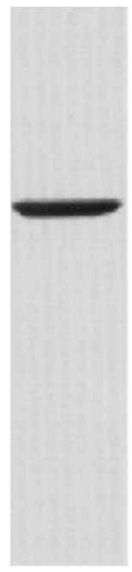

B

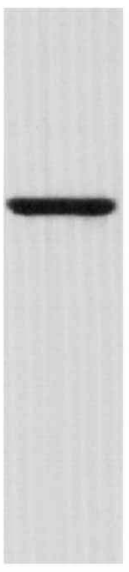

C

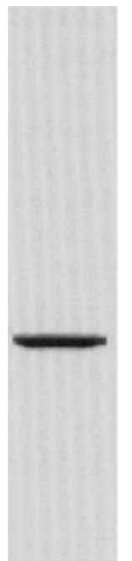

D
Fig. 6. Immunoblot for detection of the Synechocystis LPD in transformed $E$. coli $\mathrm{DH} 5 \alpha \mathrm{MCR}$ cells. $E$. coli $\mathrm{DH} 5 \alpha \mathrm{MCR}$ was transformed with pAE38 (lane B), pAE26 (lane C) or PAE26Km ${ }^{R}$ (lane D). Lane A, untransformed $E$. coli DH5 $\alpha M C R$. After growth, the spheroplast fraction was submitted to SDS-PAGE $(30 \mu \mathrm{g}$ protein in each lane). Subsequently, proteins were transferred to nitrocellulose and immunostained with anti-LPD antiserum (dilution 1:1000).

all copies of the $l p d A$ gene were eliminated from the polyploid genome. The heteroallelic Synechocystis mutant studied, which had a reduced LPD activity, caused an acidification of the growth medium. On the basis of the results presented here and of results previously published by other groups showing that a functional 2oxoglutarate dehydrogenase complex is absent in cyanobacteria (Smith, 1973), it seems likely that the LPD is a constituent of a PDC (Patel \& Roche, 1990). A reduced PDC activity would lead to accumulation of pyruvate and subsequently of phosphoenolpyruvate and 3-phosphoglyceric acid, and after carboxylation of phosphoenolpyruvate also to accumulation of oxaloacetate. If such an accumulation of mono- and dicarboxylic acids should occur in the mutant as a consequence of a limited PDC activity, then it is likely that these metabolites are partially excreted into the medium, causing the observed acidification. An accumulation of acidic metabolites as a consequence of inactive 2-oxoacid dehydrogenases, leading to various forms of metabolic acidosis, has

Table 4. Determination of the LPD activity in E. coli DH5 $\alpha M C R$ transformed with pAE38, pAE26 or pAE26Km ${ }^{R}$

\begin{tabular}{|c|c|c|c|c|}
\hline \multirow[t]{2}{*}{ Preparation } & \multicolumn{4}{|c|}{ LPD activity [units (mg protein $)^{-1}$ ] } \\
\hline & DH5 $\alpha$ MCR & $\operatorname{DH} 5 \alpha \operatorname{MCR}\left(\mathrm{pAE} 26 \mathrm{Km}^{\mathrm{R}}\right)$ & DH5 $\alpha$ MCR(pAE38) & DH5 $\alpha M C R(p A E 26)$ \\
\hline Total cell extract & $0 \cdot 13$ & $0 \cdot 10$ & $2 \cdot 69$ & $3 \cdot 68$ \\
\hline Spheroplast fraction & $0 \cdot 13$ & $0 \cdot 09$ & $2 \cdot 64$ & $3 \cdot 64$ \\
\hline $\begin{array}{l}\text { Periplasmic fraction } \\
\text { (soluble proteins) }\end{array}$ & $0 \cdot 00$ & $0 \cdot 01$ & 0.04 & $0 \cdot 04$ \\
\hline
\end{tabular}


already been described in the literature (Robinson et al., 1977; Yeaman, 1986; Patel et al., 1995).

Very little is known about the function of PDC in cyanobacteria. Bothe \& Nolteernsting (1975) described an NAD-dependent pyruvate dehydrogenase activity in Anacystis nidulans, but the enzyme was not further investigated. Since higher-plant chloroplasts contain a PDC (Taylor et al., 1992; Camp \& Randall, 1985) and since it is assumed that chloroplasts have evolved from cyanobacteria (or from a precursor form of cyanobacteria) (Douglas, 1994), the presence of a PDC in at least some cyanobacteria is very likely. The inability to clearly detect such a PDC by activity measurements in cyanobacteria might be related to an unusual location of the LPD (and possibly of the total PDC). Our immunocytochemical investigations with Synechocystis PCC 6803 (Engels et al., 1997) have indicated that the LPD is located between the cytoplasmic membrane and the peptidoglycan layer, implying that the LPD is associated with the outer (and not with the inner) side of the cytoplasmic membrane. It is well documented in the literature that PDCs can be found associated with the $\mathrm{NADH}$ : ubiquinone oxidoreductase (complex I) of the respiratory system of the mitochondrial inner membrane (Sumegi \& Srere, 1984). However, if in Synechocystis PCC 6803 such an association of the suggested PDC with the respiratory system might exist, then at least the LPD is located on the periplasmic side of the cytoplasmic membrane. Possibly, the low and hardly measurable PDC activity in broken Synechocystis cells could be explained by assuming that a partial dissociation of the PDC from the membrane occurs and that optimal activity is only obtained when a tight interaction of the PDC with the membrane is maintained. This aspect requires further investigation.

The essential nature of the LPD (which is probably a constituent of an unusual PDC) implies that under photoautotrophic growth conditions Synechocystis PCC 6803 has no functional pyruvate:ferredoxin (or flavodoxin) oxidoreductase, as described for several Anabaena species (Schmitz et al., 1993; Bauer et al., 1993), although comparative DNA sequence analysis revealed that a homologue DNA sequence to such an enzyme is present. Basepairs 3128396-3131985 of the Synechocystis PCC 6803 genome (database accession number sll0741) have $69 \%$ identity to the nifJ gene of Anabaena sp. 7120 (accession number L14925), which, however, is expressed during iron starvation only (Bauer et al., 1993).

In conclusion, our results showing that LPD is an essential enzyme in Synechocystis PCC 6803, and that a reduced LPD activity leads to an acidification of the culture medium, suggest that the LPD is a constituent in a PDC. This interpretation is supported by the identification of the genes in Synechocystis PCC 6803 encoding E1 (pyruvate decarboxylase: $\alpha$ and $\beta$ subunits) and E2 (dihydrolipoyl transacetylase) of the PDC (database accession numbers sll1712, slr1934 and sll1841: Genome Database of Synechocystis sp. strain PCC 6803). Thus, all genes encoding the three enzymes of a PDC are present in Synechocystis PCC 6803. This makes the presence of a functional PDC in Synechocystis PCC 6803 highly likely. However, the cyanobacterial PDC is unusual in that the complex (or at least the LPD) is localized in the periplasmic space. For a final answer of the question whether the LPD in Synechocystis actually functions in a PDC, the localization of the E1 and E2 enzymes of a PDC has to be investigated.

\section{ACKNOWLEDGEMENTS}

A.E. is grateful for a fellowship from the Landesgraduiertenförderungsgesetzes des Landes Nordrhein-Westfalen. The authors thank Professor A. Pühler for the kind gift of plasmid pSVB30 and for allowing the DNA sequencing in his laboratory. The synthesis of the oligonucleotide by Ms $M$. Bellanco-Garcia and a gift of plasmid pWJ31 from Dr W. Jäger are gratefully acknowledged. Moreover, the authors thank Dr Rainer Bockholt for many stimulating and helpful discussions.

\section{REFERENCES}

Altschul, S. F., Gish, W., Miller, W., Myers, E. W. \& Lipman, D. J. (1990). Basic local alignment search tool. $J \mathrm{Mol}$ Biol 215, 403-410.

Arnold, W. \& Puhler, A. (1988). A family of high-copy-number plasmid vectors with single end-label sites for rapid nucleotide sequencing. Gene 70, 171-179.

Bauer, C. C., Scappino, L. \& Haselkorn, R. (1993). Growth of the cyanobacterium Anabaena on molecular nitrogen: NifJ is required when iron is limited. Proc Natl Acad Sci USA 90, $8812-8816$.

Beaucage, S. L. \& Caruthers, M. H. (1981). Desoxynucleoside phosphoramidites - a new class of key intermediates for deoxypolynucleotide synthesis. Tetrahedron Lett 22, 1859-1862.

Benen, J. A. E., Van Berkel, W. J. H., Van Dongen, W. M. A. M., Muller, F. \& De Kok, A. (1989). Molecular cloning and sequence determination of the $l p d$ gene encoding lipoamide dehydrogenase from Pseudomonas fluorescens. J Gen Microbiol 135, 1787-1797.

Block, M. A. \& Grossman, A. R. (1988). Identification and purifcation of a derepressible alkaline phosphatase from Anacystis nidulans R2. Plant Physiol 86, 1179-1184.

Bothe, H. \& Nolteernsting, U. (1975). Pyruvate dehydrogenase complex, pyruvate:ferredoxin oxidoreductase and lipoic acid content in microorganisms. Arch Microbiol 102, 53-57.

Bourguignon, J., Macherel, D., Neuburger, M. \& Douce, R. (1992). Isolation, characterization, and sequence analysis of a cDNA clone encoding L-protein, the dihydrolipoamide dehydrogenase component of the glycine cleavage system from pea-leaf mitochondria. Eur J Biochem 204, 865-873.

Burnap, R., Koike, H., Sotiropoulou, G., Sherman, L. A. \& Inoue, Y. (1989). Oxygen evolving membranes and particles from the transformable cyanobacterium Synechocystis sp. PCC6803. Photosynth Res 22, 123-130.

Camp, P. J. \& Randall, D. D. (1985). Purification and characterization of the pea chloroplast pyruvate dehydrogenase complex. A source of acetyl-CoA and NADH for fatty acid synthesis. Plant Physiol 77, 571-577. 
Carothers, D. J., Pons, G. \& Patel, M. S. (1989). Dihydrolipoamide dehydrogenase: functional similarities and divergent evolution of the pyridine-disulphide oxidoreductases. Arch Biochem Biophys 268, 409-425.

Danson, M. J. (1988). Dihydrolipoamide dehydrogenase: a 'new' function for an old enzyme? Biochem Soc Trans 16, 87-89.

Danson, M. J., McQuattie, A. \& Stevenson, K. J. (1986). Dihydrolipoamide dehydrogenase from halophilic archaebacteria: purification and properties of the enzyme from Halobacterium halobium. Biochemistry 25, 3880-3884.

Danson, M. J., Conroy, K., McQuattie, A. \& Stevenson, K. J. (1987). Dihydrolipoamide dehydrogenase from Trypanosoma brucei. Characterization and cellular location. Biochem $J$ 243, 661-665.

Douglas, S. E. (1994). Chloroplast origins and evolution. In The Molecular Biology of Cyanobacteria, pp. 91-118. Edited by D. A. Bryant. Dordrecht, Boston \& London: Kluwer.

Eisenberg, D., Schwarz, E., Komaromy, M. \& Wall, R. (1984). Analysis of membrane and surface protein sequences with hydrophobic moment plot. J Mol Biol 179, 125-142.

Else, A. J., Hough, D. W. \& Danson, M. J. (1993). Cloning, sequencing, and expression of Trypanosoma brucei dihydrolipoamide dehydrogenase. Eur J Biochem 212, 423-429.

Engels, D. H., Lott, A., Schmid, G. H. \& Pistorius, E. K. (1994). Inactivation of the water-oxidizing enzyme in manganese stabilizing protein-free mutant cells of the cyanobacterium Synechococcus PCC 7942 and Synechocystis PCC 6803 during dark incubation and conditions leading to photoactivation. Photosynth Res 42, 227-244.

Engels, A., Kahmann, U., Ruppel, H. G. \& Pistorius, E. K. (1997). Isolation, partial characterization and localization of a dihydrolipoamide dehydrogenase from the cyanobacterium Synechocystis PCC 6803. Biochim Biophys Acta 1340, 33-44.

Fox, B. \& Walsh, C. T. (1982). Mercuric reductase: purification and characterization of a transposon-encoded flavoprotein containing an oxidation-reduction-active disulfide. J Biol Chem 257, 24982503.

Ghassemian, M. \& Straus, N. A. (1996). Fur regulates the expression of iron-stress genes in the cyanobacterium Synechococcus sp. strain PCC 7942. Microbiology 142, 1469-1476.

Grant, S. G. N., Jessee, J., Bloom, F. G. \& Hanahan, D. (1990). Differential plasmid rescue from transgenic mouse DNAs in Escherichia coli methylation-restriction mutants. Proc Natl Acad Sci USA 87, 4645-4649.

Grimme, L. H. \& Boardman, N. K. (1972). Photochemical activities of a particle fraction $\mathrm{P}_{1}$ obtained from the green alga Chlorella fusca. Biochem Biophys Res Commun 49, 1617-1620.

Hein, S. \& Steinbuchel, A. (1994). Biochemical and molecular characterization of the Alcaligenes eutrophus pyruvate dehydrogenase complex and identification of a new type of dihydrolipoamide dehydrogenase. J Bacteriol 176, 4394-4408.

Holmes, C. F. G. \& Stevenson, K. J. (1986). The amino acid sequence encompassing the active-site histidine residue of lipoamide dehydrogenase from Escherichia coli labelled with a bifunctional arsenoxide. Biochem Cell Biol 64, 509-514.

Jackman, S. A., Hough, D. W., Danson, M. J., Stevenson, K. J. \& Opperdoes, F. R. (1990). Subcellular localisation of dihydrolipoamide dehydrogenase and detection of lipoic acid in bloodstream forms of Trypanosoma brucei. Eur J Biochem 193, 91-95.

Jorgensen, R. A., Rothstein, S. J. \& Reznikoff, W. S. (1979). A restriction enzyme cleavage map of $\operatorname{Tn} 5$ and location of a region encoding neomycin resistance. Mol Gen Genet 177, 65-72.

Karplus, P. A. \& Schulz, G. H. (1987). Refined structure of glutathione reductase at $1.54 \AA$ resolution. $J$ Mol Biol 195, 701-729.

Kikuchi, H. \& Hiraga, K. (1982). The mitochondrial glycine cleavage system. Unique features of the glycine decarboxylation. Mol Cell Biochem 45, 137-149.

Kruger, N., Oppermann, F. B., Lorenzl, H. \& Steinbuchel, A. (1994). Biochemical and molecular characterization of the Clostridium magnum acetoin dehydrogenase enzyme system. J Bacteriol 176, 3614-3630.

Kubo, A., Sano, T., Saji, H., Hikaru, S., Kunisuke, T., Kondo, N. \& Tanaka, K. (1993). Primary structure and properties of glutathione reductase from Arabidopsis thaliana. Plant Cell Physiol 34, 1259-1266.

Kyte, J. \& Doolittle, R.-F. (1992). A simple method for displaying the hydrophobic character of a protein. J Mol Biol 157, 105-132.

Laddaga, R. A., Chu, L., Misra, T. K. \& Silver, S. (1987). Nucleotide sequence and expression of the mercurial-resistance operon from Staphylococcus aureus plasmid pI258. Proc Natl Acad Sci USA 84, 5106-5110.

Laemmli, U. K. (1970). Cleavage of structural proteins during the assembly of the head of bacteriophage T4. Nature 227, 680-685.

Luinenburg, I. \& Coleman, J. R. (1990). A requirement for phosphoenolpyruvate carboxylase in the cyanobacterium Synechococcus PCC 7942. Arch Microbiol 154, 471-474.

Matteucci, M. D. \& Caruthers, M. H. (1981). Synthesis of deoxyoligonucleotides on a polymer support. J Am Chem Soc 103, 3185-3191.

Mattevi, A., Schierbeek, A. J. \& Hol, W. G. J. (1991). The refined crystal structure of Azotobacter vinelandii lipoamide dehydrogenase at $2 \cdot 2 \AA$ resolution. A comparison with the structure of glutathione reductase. J Mol Biol 220, 974-995.

Mattevi, A., Obmolova, G., Sokatch, J. R., Betzel, C. \& Hol, W. G. J. (1992). The refined crystal structure of Pseudomonas putida lipoamide dehydrogenase complexed with $\mathrm{NAD}^{+}$at $2.45 \AA$ resolution. Proteins 13, 336-351.

Mattevi, A., Obmolova, G., Kalk, K. H., van Berkel., W. J. H. \& Holl, W. G. J. (1993). Three-dimensional structure of lipoamide dehydrogenase from Pseudomonas fluorescens at $2 \cdot 8 \AA$ resolution. Analysis of redox and thermostability properties. $J \mathrm{Mol}$ Biol 230, 1200-1215.

Miller, J. H. (1972). Experiments in Molecular Genetics. Cold Spring Harbor, NY: Cold Spring Harbor Laboratory.

Myers, E. W. \& Miller, W. (1988). Optimal alignment in linear space. Comput Appl Biosci 4, 11-18.

Otulakowski, G. \& Robinson, B. H. (1987). Isolation and sequence determination of cDNA clones for porcine and human lipoamide dehydrogenase. Homology to other disulfide oxidoreductases. $J$ Biol Chem 262, 17313-17318.

Patel, M. S. \& Roche, T. E. (1990). Molecular biology and biochemistry of pyruvate dehydrogenase complexes. FASEB J 4, 3224-3233.

Patel, M. S., Naik, S., Wexler, I. D. \& Kerr, D. S. (1995). Gene regulation and genetic defects in the pyruvate dehydrogenase complex. J Nutr 125, 1735S-1757S.

Rao, M.-J.-K. \& Argos, P. (1986). A conformational preference parameter to predict helices to integral membrane proteins. Biochim Biophys Acta 869, 197-214.

Richarme, G. \& Heine, H.-G. (1986). Galactose- and maltose- 
stimulated lipoamide dehydrogenase activities related to the binding-protein-dependent transport of galactose and maltose in toluenized cells of Escherichia coli. Eur J Biochem 156, 399-405.

Robinson, B. H., Taylor, J. \& Sherwood, G. (1977). Deficiency of dihydrolipoyl dehydrogenase (a component of the pyruvate and $\alpha$-ketoglutarate dehydrogenase complexes): a cause of congenital chronic lactic acidosis in infancy. Pediatr Res 11, 1198-1202.

Sambrook, J., Fritsch, E. F. \& Maniatis, T. (1989). Molecular Cloning: a Laboratory Manual, 2nd edn. Cold Spring Harbor, NY: Cold Spring Harbor Laboratory.

Schirmer, R. H. \& Schulz, G. E. (1987). Pyridine nucleotide-linked sulfur metabolism. In Pyridine Nucleotide Coenzymes: Chemical, Biochemical and Medical Aspects, vol. B, pp. 333-379. Edited by D. Dolphin, R. Poulson \& O. Avramovic. New York: Wiley.

Schmitz, O., Kentemich, T., Zimmer, W., Hundeshagen, B. \& Bothe, H. (1993). Identification of the nifJ gene coding for pyruvate: ferredoxin oxidoreductase in dinitrogen-fixing cyanobacteria. Arch Microbiol 160, 62-67.

Schulz, G. E., Schirmer, R. H., Sachsenheimer, W. \& Pai, E. F. (1978). The structure of the flavoenzyme glutathione reductase. Nature 273, 120-124.

Serrano, A. (1992). Purification, characterization and function of dihydrolipoamide dehydrogenase from the cyanobacterium Anabaena sp. strain PCC 7119. Biochem J 288, 823-830.

Shames, S. L., Fairlamb, A. H., Cerami, A. \& Walsh, C. T. (1986). Purification and characterization of trypanothione reductase from Crithidia fasciculata, a newly discovered member of the family of disulphide-containing flavoprotein reductases. Biochemistry 25, 3519-3526.

Smith, A. J. (1973). Synthesis of metabolic intermediates. In The Biology of Blue-green Algae, pp. 1-38. Edited by N. G. Carr \& B. A. Whitton. Oxford: Blackwell Scientific Publications.

Smith, P. K., Krohn, R. I., Hermanson, G. T., Mallia, A. K., Gartner, F. H., Provenzano, M. D., Fujimoto, E. K., Goecke, N. M., Olson, B.
J. \& Klenk, D. C. (1985). Measurement of protein using bicinchoninic acid. Anal Biochem 150, 76-85.

Staden, R. (1986). The current status and portability of our sequence handling software. Nucleic Acids Res 14, 217-232.

Sumegi, B. \& Srere, P. A. (1984). Complex I binds mitochondrial NAD-coupled dehydrogenases. J Biol Chem 259, 15040-15045.

Taylor, A. E., Cogdell, R. J. \& Lindsay, J. G. (1992). Immunological comparison of the pyruvate dehydrogenase complexes from pea mitochondria and chloroplasts. Planta 188, 225-231.

Thieme, R., Pai, E. F., Schirmer, R. H. \& Schulz, G. E. (1981). Threedimensional structure of glutathione reductase at $2 \AA$ resolution. J Mol Biol 152, 763-782.

Turner, S. R., Ireland, R. \& Rawsthorne, S. (1992). Purification and primary amino acid sequence of the $L$ subunit of glycine decarboxylase. Evidence for a single lipoamide dehydrogenase in plant mitochondria. J Biol Chem 267, 7745-7750.

Williams, C. H., Jr (1976). Flavin-containing dehydrogenases. In The Enzymes, vol. 13, 3rd edn, pp. 89-172. Edited by P. D. Boyer. New York: Academic Press.

Williams, C. H., Jr (1991). Lipoamide dehydrogenase, glutathione reductase, thioredoxin reductase, and mercuric ion reductase - a family of flavoenzyme transhydrogenases. In Chemistry and Biochemistry of Flavoenzymes, vol. III, pp. 121-211. Edited by F. Müller. Boca Raton, FL: CRC Press.

Williams, J. G. K. (1988). Construction of specific mutations in photosystem II photosynthetic reaction center by genetic engineering methods in Synechocystis 6803. Methods Enzymol 167, 766-778.

Yeaman, S. L. (1986). The mammalian 2-oxoacid dehydrogenases: a complex family. Trends Biochem Sci 11, 293-296.

Received 6 December 1996; revised 29 April 1997; accepted 26 June 1997. 